\title{
ROW HOUSE FIREFIGHTING TACTICS
}

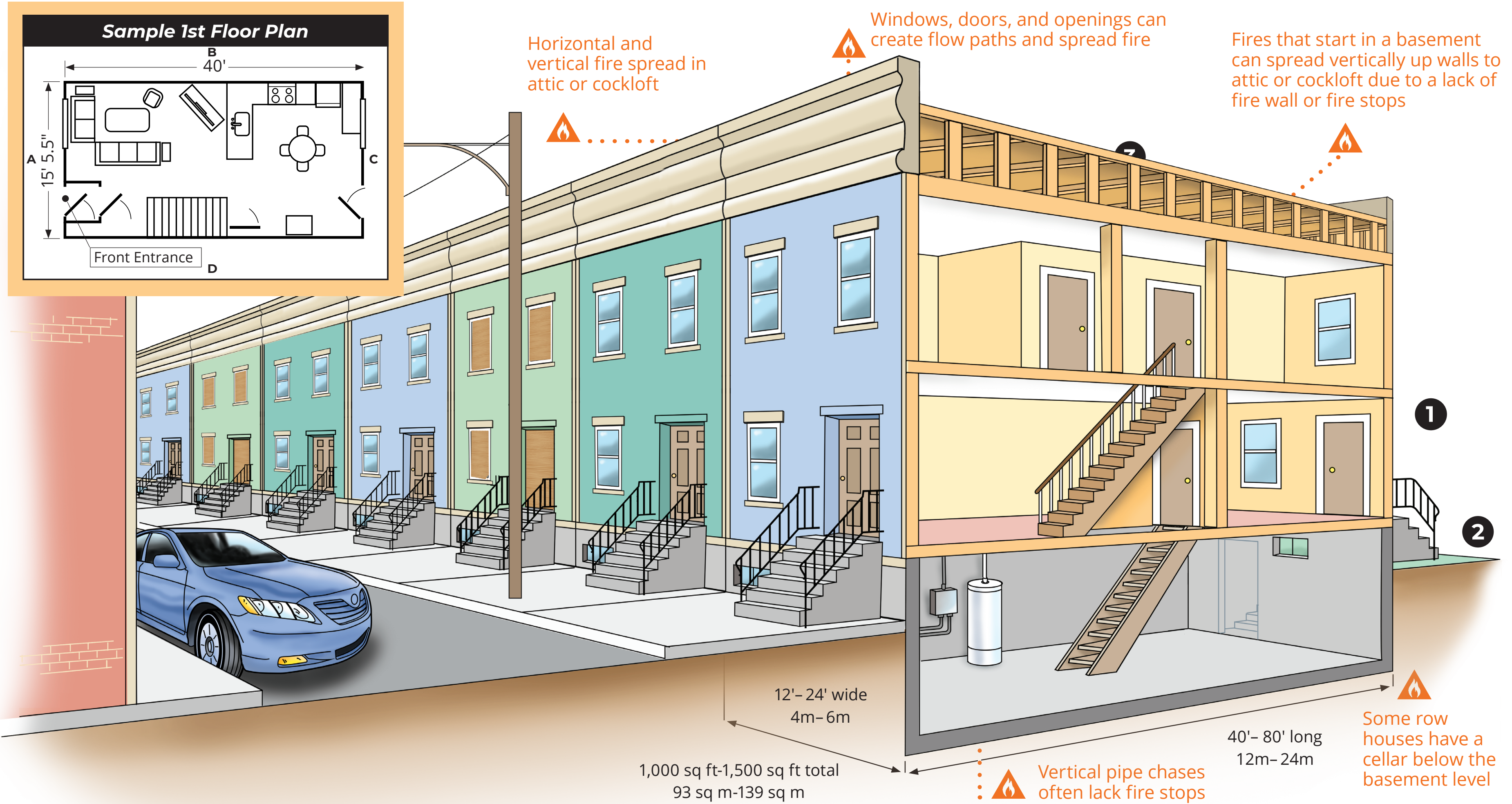

$93 \mathrm{sq} \mathrm{m}-139 \mathrm{sq} \mathrm{m}$

FIREFIGHTERS

STAY SAFE

FOLLOW THESE

6 TACTICS

1
If interior
unit, size-up
Sides A and C;
locate fire and
extent; send
resources to
Side C

(2) Hoseline deployment:

$\begin{array}{ll}\text { A. Fight fire on the level } & \text { D. Side } \mathrm{C} \text { through alley } \\ \text { of the fire (exterior } & \text { or adjoining house }\end{array}$ of the fire (exterior attack may be mos effective initially)

B. Protect search

C. Basement window or door
E. Backup hoseline ready

F. Use cellar nozzle to get water into below grade areas

G. Use piercing or cockloft nozzle to get water into void spaces

Note: Numbered tactics are not prioritized.

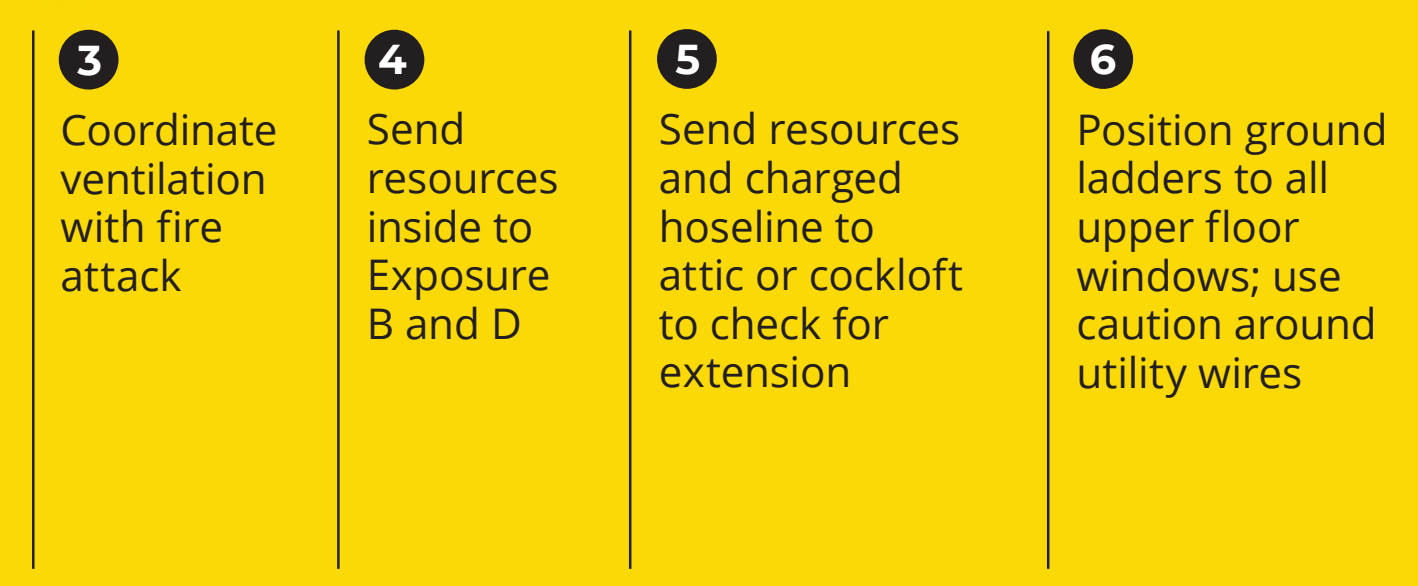

TYPICAL FEATURES

\section{EXTERIOR \\ ROW HOUSE}

NARROW WINDOWS

FRONT STOOP (STEPS)

leads to street

2ND \& 3RD FLOOR 'BAY'

3 or more windows that

extend from the structure

ORNATE CORNICES

SINGLE SLOPING ROOF

modest ornate wood

or brick cornice

\section{INTERIOR \\ ROW HOUSE}

SINGLE RUN, STEEP STAIRS

LONG, NARROW HALLWAYS

WALKOUT BASEMENT

BASEMENT and/or CELLAR

used for storage

CELLAR

only accessible from

the basement

\section{CONSTRUCTION \\ AND MATERIALS}

\section{BALLOON}

frame construction

BUILDING PERIOD

late 1800 s to early 1900s

BRICK EXTERIOR WALLS

SOLID WOOD BEAM

floor joists and roof rafters

PLASTER and LATH

over wood framing

TYPE III CONSTRUCTION

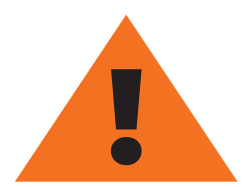

Conduct a community risk assessment to understand unique features of row houses in your jurisdiction. Row house modernization efforts may mean the exterior is refaced and interior has a different floor interior has a different floor plan. Materials used for modernization or new row house construction may burn more quickly.

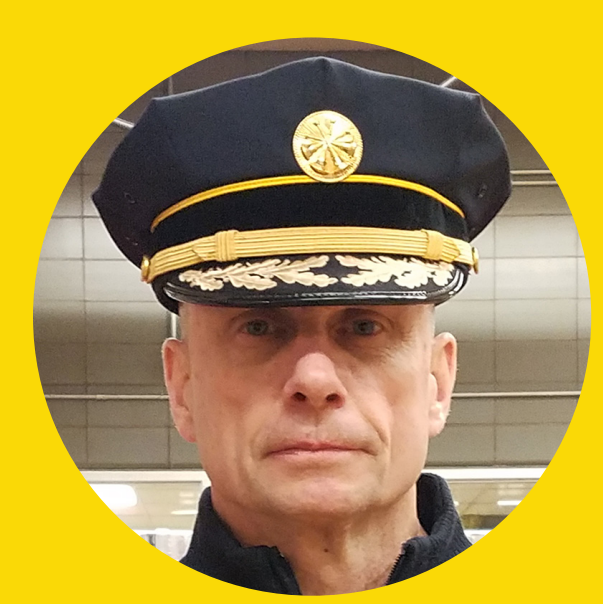

'Don't underestimate the danger to firefighters when fighting a row house fire. Access to the rear of the property is a major challenge. Basement and cellar fires in row houses have resulted in many line of duty deaths. You must be diligent and prepare as though you're going to a fire each time you report for duty. II

Assistant Chief Harry Bannan Philadelphia Fire Department, Platoon D

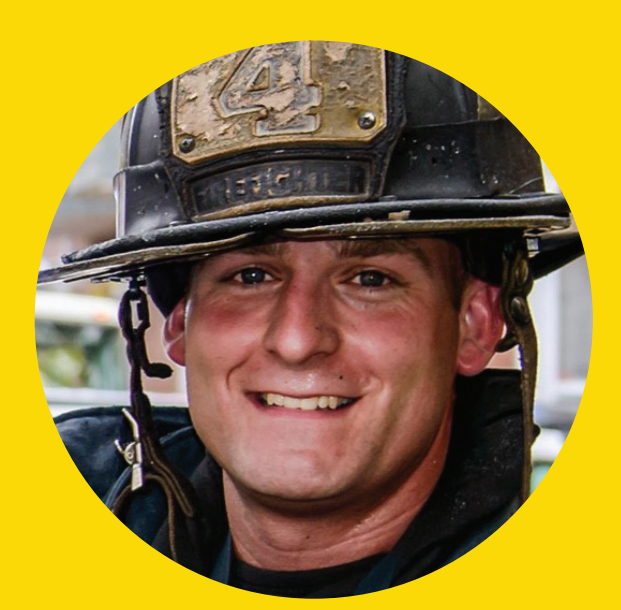

I Basic skills - quick, proficient hoseline deployment and advancement - aggressive searches. Firefighters must perform these skills effectively when fighting row home fires. 'I

Firefighter Vincent DeNisio Wilmington, DE Fire Department,
MORE INFORMATION colc.gov/niosh/fire/ $f(0)$ Follow us on Facebook, Instagram or Twitter @NIOSH

Acknowledgements: Assistant Chief Bannan and the Philadelphia Fire Department and Firefighter DeNisio and the Wilmington, DE Fire Department for their support with this material.
UL Basement Fire Video

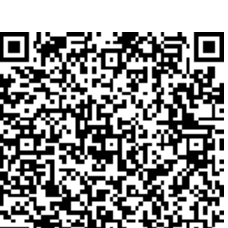

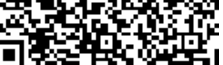

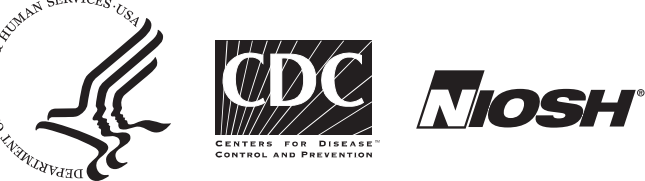

